\title{
Looking Into the Hiring Bias - Is Fertility Desire an Important Cause of Gender Discrimination in Chinese Labor Market?
}

\author{
Boru Chen
}

\author{
Goldsmiths, University of London, London, SE14 6NW, UK, bchen001@ gold.ac.uk
}

ABSTRACT

Hiring Bias has always been a popular topic. Especially in recent years, it has aroused great concerns from all walks of the society as the development of economy and culture. It is undeniable that women still somewhat suffer from discrimination in the employment. In China, some of the younger generation even choose to voluntarily state that they have no plans to have children in the next few years to ensure that they can avoid hiring discrimination as much as possible and thus get hired. From this phenomenon, we generate the idea that design an experiment to explore the influencing factors in hiring bias under the context of Chinese labour market. In this work, we develop a preliminary hypothesis that becoming pregnant and taking maternity leave is a significant factor of hiring bias, and try to use filed study to conduct the experiment. Basically, we propose to send resumes to real job openings of entry-level positions in real estate industry during the season of campus recruiting and measure the call-back rates. This work is a 2 by 2 design with male and female resumes and either with or without an additional statement saying that the applicant does not plan to have children. The predicted result is male has a higher call-back rate than female in general, while call-back rate of female-with-statement are higher than female-without-statement, which is the same in male group. But the difference between call-back rates of with-statement and without-statement are lower than female's. As a conclusion, gender discrimination exists during the hiring process while becoming pregnant and taking maternity leave is a significant factor. And potential gender bias does exist in employment which has already turned into discrimination against women and fertility. Through this study, we expect to gain a deeper understanding of hiring bias and find out the significant influencing factor, so that we can better improve the current situation of gender discrimination in Chinese labor market.

Keywords: Fertility desire, gender discrimination, hiring bias, maternity leave.

\section{INTRODUCTION}

Employment is closely related to almost everyone's life, while women are often in a weak position under employment situation. Research has found that the initial employment rate of male college students is $10 \%$ higher than that of female college students[1]. According to zhaopin.com, 58\% of women were asked about marital and fertility status when applying for a job, $27 \%$ of women have experienced employers restricting the gender of their positions, while both of the rates are significantly higher than men's[2]. Yang also claims that more than half of women have encountered the unreasonable demand of "no marriage or child within a certain year" when applying for a job[3]. Additional to explicit discrimination, there are various realities, such as employers receiving resumes at the job fair, but not notifying women to come for an interview; or after the interview, employers adjusting internally and rejecting women, while the reason given is only "need more professional people"; even if hiring the women, employers only allowing women to do the office work or administrative affairs; regarding the regulation of equal pay for men and women, employers will use "company policies" or "privacy can not to be disclosed" as reasons to cover up the facts. These also vividly shows the tough situation that women have been facing. Both explicit and implicit discrimination and lack of right protection has brought serious and negative impact on those women. According to Green Paper on the Mental Well-Being of Chinese Career Woman in 2019, after conducting an online questionnaire survey of 1199 
working women aged $20-59$, more than $80 \%$ of working women have experienced symptoms of anxiety or depression in the past year, and about $30 \%$ of them "feel anxiety and depression from time to time", $7 \%$ of women even indicated that they are "always in a state of anxiety or depression"[4]. Therefore, is there any gender-related bias in employment? Has this kind of bias evolved into discrimination? Under this context, we try to look into the gender bias in hiring, especially in the process of $\mathrm{CV}$ screening, and figure out what role does fertility desire play. This is a field study focusing on the industry of real estate, we send fictitious resumes to real job openings and record the responses from employers. If the preference for those who indicated no-kids over those who didn't can be found, then gender discrimination exists during the hiring process while becoming pregnant and taking maternity leave is a significant factor.

\section{LITERATURE REVIEW}

Quite a few scholars have made studies and researches regarding to the topic of hiring bias, both in China and other countries. Yang analyzed the different forms of discrimination and its social impacts in the recruitment of female college students through surveys and interviews[3]. Miao also focused on similar topic, discussing the current employment situation of female college students and methodologies to improve[1]. Wei interpreted gender discrimination in employment and its causes from the perspective of human resource management, including how fertility puts women in a disadvantaged position[5]. In addition, Yang \& Sun proposed the analytical framework "gender-motherhood double taxation" to interpret various inequalities in work and the impact of fertility on women[6]. Greenhaus \& Beutell proposed a model of work-family conflict. These all helped me have a better understanding when interpreted the results[7]. Apart from those papers, many researches in terms of the other factors in hiring bias provided inspirations on our experiment design. When looking at previous studies related to various bias in hiring, field study is a common method when deal with these topics. Besides, Carlsson \& Eriksson, Agerström \& Rooth, and Bertrand \& Mullainathan all used the method of sending fictitious resumes to real job openings to look into the bias[8-10]. Thus, this study adopted the method of field study. However, although there were many researches on employment of college graduate and gender bias, only a few gender-related research were specifically about real estate industry. Therefore, this study was not only to explore the fertility desire in hiring, but also to make up this lack.

\section{HYPOTHESES}

\section{Hypothesis 1}

Even in entry-level positions, preference for men is still over women.

\section{Hypothesis 2}

Women present more complicated internal traits, while women with pregnancy intention will be more discriminated in hiring.

\section{Hypothesis 3}

Men present similar traits to women, which means men will also encounter more discrimination in hiring because of their family plan. But fertility desire has far less impact on men than women.

\section{METHODS}

\subsection{Target Job}

Given that the more equally likely to hire men and women that the industry and jobs, the clearer changement tends to be when variable is introduced, we chose this industry and the entry-level positions. Therefore, all the resumes targeted at the jobs of sales in the top 50 real estate enterprises in Shanghai by the official ranking[11].

\subsection{Resumes Appearance and design}

To control the variables and minimize the influence on result, we tired to make all the contents except the family plan as common as possible. All the came in order under the Basic Information session: names on applications were random combination from 100 most common surnames and 10 most-used male/female given name by official national names report[12]; gender and marital status were directly indicated, which is a norm under such cultural and social context, and all the marital status were unmarried and childless; ages were set as 23-25, which is the typical fresh graduates age. Meanwhile, the younger generation can help the no-kids-statement seems less unusual; height of female were from $155 \mathrm{~cm}$ to $175 \mathrm{~cm}$, male were from $165 \mathrm{~cm}$ to $185 \mathrm{~cm}$, which is the common requirement; weight were calculated according to the standard BMI $(18.5,24)[13]$; degrees were set as undergraduates, which is the most common degree of this job in first tir city[14]; finally was the contact(phone number, email, etc.).

Using indirect ways to indicate pregnancy intention may cause introduction of new variables and unintended variables replacement, leading to new bias. In order to avoid this, we decided to use the concise sentence "no plan to have a child in 5 years" to signal the family plan straightforward. There were two situations of resume submission: if is online application, which means the 
resumes are submitted by filling in the standardized form online, then we shall follow the prescribed format and remark the sentence at the end of the Self Evaluation section or the Career Plan section; if is voluntarily submission, we shall follow the order of Basic Information, Summary Statement, Education, Work Experience, Skills (basically at the same level to further control the variables), then put the sentence as the last bullet point of the Summary Statement section.

\subsection{Measures}

This was a field study and we measured the call back rates, which were the percentage of valid callbacks. Calls or emails received for getting hired were regarded as valid callbacks, and calls or emails received for rejection or no response were regarded as invalid callbacks. Callbacks were the preference of the employers, therefore, the lower the callback rate were, the more significant the discrimination.

The overall design was $2 \times 2$ (male-with-statement, male-without-statement, female-with-statement, and female-without-statement). Finally, we got 400 outcomes.

Divided all data into two groups according to with or without the statement, and compared the data of these two groups to analyze whether there is gender discrimination against fertility, because the only variable then was statement.

Divide all data into two groups according to gender, and compare the data of these two groups to analyze whether there is gender discrimination against women, because the only variable then was gender.

Divided all data into two groups according to gender, and calculated the D-value between statement and no-statement within each groups, then compared to analyze whether there is gender discrimination against both woman and fertility.

\subsection{Procedure}

The experiment was held from September to October, which is well-known as the season of campus recruiting. This is also the time when the majority of fresh graduates were intensively seeking jobs while the company were providing a large number of positions.

100 different resumes were designed as mentioned above, and then each was adjusted into four versions according to the $2 \times 2$ design, which means there were 100 male-with-statement resumes, 100 male-without-statement resumes, 100 female-with-statement resumes, and 100 female-without-statement resumes. In this way, we got 400 resumes. Among them, every four copies are exactly the same except for gender and family plan, so these 400 resumes cannot appear in pairs in the same company at the same time.

50 positions in 50 companies were chosen in total, and 8 resumes were submitted for each company. This means, for each company, we applied one position with 8 resumes of different candidates, containing 2 groups of 4 versions, then we repeated this to 50 companies.

We recorded the results based on the replies received by phone or email. When the employer notified us to participate in the interview, we declined by the reason that "has already got another job" to reduce the inconvenience caused to them. For the purpose of following the ethic principle, after the experiment was completed, we all sent emails to let employers know that it was an experiment, and meanwhile informed them of the true purpose of the experiment.

\subsection{Limitations}

We have made a lot of efforts to reduce the unusualness of directly indicating the family plan. However, it is undeniable that this behavior is still not completely common in the current recruitment situation. Then, we signaled women with pregnancy intentions by no specially statement, instead of indicating the family plan correspondingly. In addition, the format of different situations of resume submission is different, which makes the possibility that hiring managers notice the statement during screening is not exactly the same. Moreover, it cannot be ruled out that some companies will think that women with statements are more determined in character and work ability, thus introducing the new variable of "hardworking and endurance". Most importantly, this study so far still seems too simple and straightforward. Thus, it is weak because it can only prove the existence of the situation, and cannot analyze the relationship between pregnancy intention and gender discrimination in detail, which requires further research.

\section{RESULTS}

\subsection{Predicted Result}

Generally, men had a higher callback rate than women. According to Wei, employers tend to believe that women are more suitable for family production than social labor, due to the influence of traditional gender ideas and stereotypes. Meanwhile, society has very low expectations of women in their careers, suggesting that they will give up the careers for their families[5]. This opinion might shows one of the reason for gender discrimination against women as this result shows. It also confirms the hypothesis 1 .

The call-back rate of those women who stated that they had no family plan was higher than that those who 
did not, which shows the gender discrimination against fertility. Generally, when an individual plays multiple roles at the same time, these roles conflict with each other and cannot meet the needs of work and family at the same time. That is to say, fertility and employment are essentially mutually exclusive[7]. From the employer's point of view, maternity leave means that they have to bear not only the direct costs of paying salaries and filling the vacancies, but also the indirect costs caused by Female employees' out-of-practice skills and not-updated knowledge after returning to work, which is incompatible with their goal of low cost and high profit. Apart from the maternity leave, Wei also point out the possibility that women would become physically and psychologically weaker during pregnancy and nursing period objectively, which might reduce work efficiency and affect company's operations[5]. It also confirms the hypothesis 2 .

The call-back rate of those men who stated that they had no family plan was higher than that those who did not as well, because the huge direct cost and indirect cost caused by maternity leave to the enterprise are the same regardless of gender. Nevertheless, regarding the difference of callback rate between those who indicated no family plan and those who did not, men are lower than women. This is because men have greater freedom of choice than women who have to rest in a physiological sense. Meanwhile, corresponding to women, men are also influenced by stereotypes and traditional ideas that the father's family role is considered to be a money earner rather than a manny[5]. Thus, these two results show the gender discrimination against woman as well as fertility. It also confirms the hypothesis 3 .

\subsection{Other Possible Result}

As one of other possible patters of result, there is no difference or only slight difference on callback rates between men who indicated their family plan and those who did not. One of the reason is that men tend to refuse taking paternity leave in order not to affect their family income, as wages are closely linked to personal performance in real estate industry. In fact, men don't even know that they can take paternity leave because of its lack of policy support and promotion at this stage. According to Xing, only 9 provinces in China explicitly encourage paternity leave, including Shanghai. However, Shanghai is not included by the only three provinces that have detailed regulations on the duration of paternity leave[15]. These have reduced the proportion of men who actually take paternity leave. Therefore, it is nearly no impact on men whether they have family plan or not.

\section{CONCLUSION}

To conclude, gender discrimination exists during the hiring process while becoming pregnant and taking maternity leave is a significant factor. And potential gender bias does exist in employment which has already turned into discrimination against women and fertility.

This topic is worthy of further research. We can carry out quantitative research to further verify the causal relationship of fertility desire and gender discrimination. At the same time, we can extend this topic and try to explore how fertility desire, as an important factor of hiring bias, will change in different industries, for instance, brain work versus manual work. In addition, we can also explore in different regions. For instance, in different geographical locations (coastal versus inland) or different economic development levels (urban versus rural), how the influence of fertility desire on hiring bias will change.

\section{REFERENCES}

[1] Miao, Y. (2020). Study on Current Employment Status and Optimization Strategy of Female College Students. Journal Of Educational Institute Of Jilin Province, 36(10), 141-144.

[2] zhaopin.com. (2020). Investigation Report of Chinese Women Working Situation. Retrieved from https://max.book118.com/html/2021/0705/6050044 134003210.shtm

[3] Yang, H. (2015). Social Impacts of Gender-Based Discrimination in Employment among Female University Students. Collection of Women's Studies, (4), 97-103.

[4] Tsinghua University International Center for Communication., \& BLACKMORES INSTITUTE. (2019). Green Paper on the Mental Well-Being of Chinese Career Woman.

[5] Wei, J. (2021). An Analysis of Sex Discrimination in the Chinese Workplace from the Perspective of Enterprise Human Resource Management. China Journal Of Commerce, (6), 140-141.

[6] Yang, J., \& Sun, C. (2019). On the "Gender-Motherhood Double Taxation"in Labor Market. Journal Of Beijing Administration Institute, (1), 93-103.

[7] Greenhaus, J H, \& Beutell, N J. (1985). Sources of Conflict between Work and Family Roles. The Academy of Management Review, 10(1), 76-88.

[8] Carlsson, M., \& Eriksson, S. (2019). In-group gender bias in hiring: Real-world evidence. Economics Letters, 185, 108686. 
[9] Agerström, J., \& Rooth, D. (2011). The Role of Automatic Obesity Stereotypes in Real Hiring Discrimination. Journal of Applied Psychology, 96(4), 790-805.

[10] Bertrand, M., \& Mullainathan, S. (2004). Are Emily and Greg More Employable than Lakisha and Jamal: A Field Experiment on Labor Market Discrimination. The American Economic Review, 94(4), 991-1013.

[11] Shanghai Real Estate Trade Association. (2017). TOP 50 REAL ESTATE ENTERPRISES OF 2015-2016 (pp. 106-107). Shanghai: Shanghai Real Estate Trade Association.

[12] The Ministry of Public Security of the People's Republic of China. (2021). Report of National Names in 2020. Retrieved from http://www.gov.cn/xinwen/2021-02/08/content_55 85906.htm

[13] National Health Commission of the People's Republic of China. (2013). Criteria of weight for adults. $\quad$ Retrieved from http://www.nhc.gov.cn/wjw/yingyang/201308/a233 d450fdbc47c5ad4f08b7e394d1e8.shtml

[14] China Alliance of Real Estate Agencies., \& Beike Research Institute. (2020). 2020 Realtor Employment Report. Retrieved from http://admin.fangchan.com/uploadfile/uploadfile/an nex/2/1927/5ed71c7114cd5.pdf

[15] Xing, C. (2021). When will Fathers Take Paternity Leave. Friend Of Science Amateurs, (5), 56-59. 